\title{
Superphanes: Facile and Efficient Preparation, Functionalization and Unique Properties
}

\author{
Aimin Li, ${ }^{\dagger}$ Yuanchu Liu, ${ }^{\dagger}$ Wei Zhou, ${ }^{\dagger}$ Yunqi Jiang, ${ }^{\dagger}$ and Qing $\mathrm{He}^{*}, \dagger$ \\ †State Key Laboratory of Chemo/Biosensing and Chemometrics, Advanced Catalytic Engineer Research Center of the \\ Ministry of Education, College of Chemistry and Chemical Engineering, Hunan University, Changsha 410082, P.R. \\ China \\ KEYWORDS: Superphane; Cyclophane; Self-assembly; Dynamic covalent bond; Fluorescence emission; host-guest; AIE;
}

\begin{abstract}
Superphanes, compounds in which the two benzene rings clamped parallel on top of each other by six bridges, have garnered considerable interest due to their aesthetically pleasing structures and unique chemical physical properties. However, until now progress in the research of superphane chemistry and beyond has been seriously hampered by their poor availability. Herein, we report the facile and scalable synthesis of a collection of superphanes with structural diversity and their unique photophysical properties, as well as their unusual host-guest behavior. Initially, a set of dodecaimino-containing superphanes 7a-7e are obtained via dynamic self-assembly of a hexakis-amine and a series of readily derived aromatic dialdehyde in one pot. The resulting superphanes are found capable of being reduced with $\mathrm{NaBH}_{4}$ to their corresponding secondary-amine versions 3a-3e. Subsequently, superphane 3c bearing 12 amine-NHs was further subject to post-functionalization with various functional groups, e.g., ethyl, allyl, propargyl and but-2-yn-1-yl. Unprecedentedly, the secondary aminebased superphanes 3a-3e were observed to exhibit genuine fluorescence both in solution and in the solid state while the imine-based superphanes 7a-7e were found to highly emissive only in solid state with fluorescent quantum yields of $3.5 \sim$ 17.1. Finally, fully protonated 3a was exemplified to encapsulate a $2 \mathrm{Cl}^{-} \cdot \mathrm{H}_{2} \mathrm{O}$ cluster both in the solid state and in solution. With the easy and versatile synthesis, modification, as well as unique photophysical and host-guest properties, we believe that this study will break the bottleneck in superphane chemistry and open the door to a novel class of supramolecular hosts and advanced functional materials on the basis of superphanes.
\end{abstract}

\section{Introduction}

Since the pioneering work of Cram in the early $1950 \mathrm{~s},{ }^{1} \mathrm{cy}-$ clophane chemistry has blossomed into an active research area and the cyclophane-based systems have spurred considerable interest in the fields of supramolecular chemistry, natural products, organometallic chemistry, asymmetric synthesis, functional $\pi$ systems, polymer chemistry, and materials science. ${ }^{2-8}$ However, as stated by Vögtle in 1972 "the ultimate achievement of work in the cyclophane field would be the synthesis of the fully bridged [2.2.2.2.2.2](1,2,3,4,5,6)cyclophane (1)" that was trivially termed as superphane initially proposed by Boekelheide and Hopf in 1979.9-10 Later, the terminology superphanes were extended and, inter alia, designate compounds in which the two benzene rings clamped parallel on top of each other by six bridges (e.g., 1, Figure 1a). ${ }^{11}$ As a tour de force in man-made organic molecules, superphanes, featuring aesthetically pleasing structures with high symmetry $\left(D_{6 h}\right)$, were initially designed as a highly strained synthetic goal for the discovery of new preparative procedures, and attractive physicochemical properties such as chemical bond, ring strain, and unusual $\pi$-electron interactions. ${ }^{11}$ In theory, superphanes could be rendered to be unique yet useful supramolecular hosts for specific guest species via well-designed extension and decoration of the toroidal bridges to furnish suitable binding cavities. Nevertheless, most, if not all, of these possibilities have been limited by their availability over the past 40 years or so. ${ }^{10,12-13}$ Therefore, developing facile, efficient, scalable and robust synthetic protocols for superphanes is key to the flourish of superphane chemistry and beyond.

Compared with the conventional supramolecular hosts such as macrocyclic receptors and cages, ${ }^{14-18}$ superphanebased supramolecular hosts are expected to have many advantages and unique characteristics. Firstly, the exceptionally high structural symmetry $\left(D_{6 h}\right.$ or $C_{6 v}$ ) may simplify its synthesis; Secondly, the highly dense binding sites (6n, where $\mathrm{n}$ is the number of binding site(s) on each bridge) may allow for tight guest binding, that is of significance to biomolecular recognition, ion extraction, and cluster stablization; ${ }^{19-22}$ Thirdly, the uniform three-dimensional distribution of the six connecting bridges around the nearclosed internal cavity may prevent the embedded species from solvation or attack by the external substates. Given the complexity and symmetry of superphanes per se, we envisioned that highly efficient and selective dynamic covalent reactions are beneficial to access such a class of complicated superstructures. ${ }^{23-26}$ Amongst them, imine dynamic chemistry proved to be particularly appealing. ${ }^{27-30}$ For example, in 2020, our group successfully introduced the imine dynamic chemistry to construct the first-ever superphane (2) 
as a supramolecular receptor for hosting either small anions or neutral species, e.g. a water dimer, via self-assembly of two simple substrates in a 2:6 ratio in one pot (Figure 1a). ${ }^{31-32}$ Almost simultaneously and independently, Badjić group reported a so-called hexapodal capsule for the recognition of anions, where the capsule was prepared through a dynamic reaction of a hexa-amine and a readily premade hexa-podal aldehyde precursor in a 1:1 fashion, coincidently, using a similar strategy. ${ }^{33}$ These two examples provided some interesting results for superphane chemistry. However, both systems 1) consist of multiple unstable and reversible amine bonds; 2) didn't show structural diversity and modification; 3) prepared in milligram scale. Thus, the best is still yet to come.

(a) Previously reported superphanes

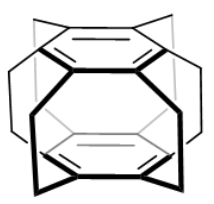

1

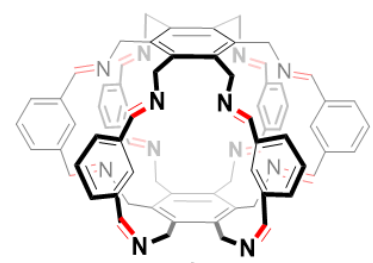

2

(b) Pre- and post-modified superphanes (this work)

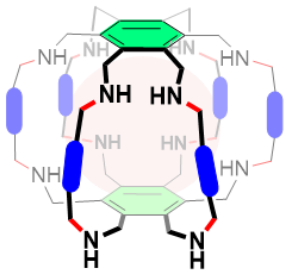

$\begin{array}{ll}\checkmark \text { Facile synthesis } & \checkmark \text { Post-functionalization } \\ \checkmark \text { Gram-scale preparation } & \checkmark \text { Structural diversity }\end{array}$

$\checkmark$ Pre-modification

$\checkmark$ Chromatography free

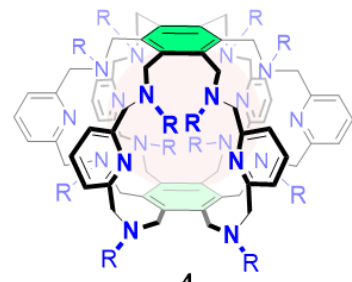
$\checkmark$ High symmetry $\checkmark$ Up to 18 binding sites $\checkmark$ Near-closed 3D cavity $\checkmark$ Host-guest binding

Figure 1. (a) Chemical structures of the previously reported superphanes $\mathbf{1}^{10}$ and $\mathbf{2}^{31-32}$. (b) Representative chemical structures of superphanes with large cavities via pre-modification (for 3 ) and post-modification (for 4) strategies reported in this work.

On the basis of our previously reported imine dynamic strategy, herein, we describe a general synthetic route accessible to a series of highly stable superphanes (3, Figure 1b) with irreversible covalent bonds via in-situ reduction of the corresponding imino-based superphanes using $\mathrm{NaBH}_{4}$ as the reductive reagent. The easy accessibility and high efficiency were exemplified with successful gram-scale preparation of the secondary-amine-based superphane $\mathbf{3 c}$, which was successfully post-functionalized with ethyl iodide, allyl bromide, propargyl bromide or 1-bromobut-2yne bromide, giving the peraza-substituted superphanes 4 (Figure 1b). Notably, the synthesis of all superphanes under current study was chromatography free. More importantly, unprecedented solid-state and solution-state fluorescent properties were also discussed. Finally, protonated superphane 3a proves capable of binding a labile trimeric chloride hydrate cluster $\left(2 \mathrm{Cl}^{-} \cdot \mathrm{H}_{2} \mathrm{O}\right)$. To the best of our knowledge, this is the first report on the facile and gramscale synthesis of superphanes that feature liquid and solid fluorescence, as well as effective encapsulation of a $2 \mathrm{Cl}^{-} \cdot \mathrm{H}_{2} \mathrm{O}$ cluster.

\section{Results and Discussion}

\section{One-pot, gram-scale synthesis and pre-modification}

According to our previously reported work, the iminocontaining superphane $\mathbf{7 a}$ could be accessible via dynamic self-assembly of hexakis-amine (5) and $m$-phthalaldehyde (6a) in a 2:6 ratio in one pot. ${ }^{32}$ Inspired by the fact that macrobicyclic azacryptands and sandwich-like azacyclophanes could be easily prepared through reversible and thermodynamically driven imine condensation, followed with a reduction step, ${ }^{34-36}$ we next sought to transform imine superphane 7a into its stable amine form. To our delight, treatment of 7a with $\mathrm{NaBH}_{4}$ in a mixture of $\mathrm{CH}_{2} \mathrm{Cl}_{2}$ and $\mathrm{CH}_{3} \mathrm{OH}$ $(1: 1, \mathrm{v} / \mathrm{v})$ at room temperature over $5 \mathrm{~h}$ led to the formation of amine superphane 3a in $81 \%$ yield (Scheme 1). Similarly, self-assembly of $\mathbf{5}$ with 5 -bromoisophthaldehyde $\mathbf{6 b}$ gave imine-based superphane $\mathbf{7 b}$ in $39 \%$ yield. After reduction with $\mathrm{NaBH}_{4}, \mathbf{7 b}$ was transformed into $\mathbf{3 b}$ in a yield of $74 \%$ (Schemes S1 and S2). Satisfyingly, we managed to further simplify the synthesis of $\mathbf{3} \mathbf{a}$ and $\mathbf{3} \mathbf{b}$ via in-situ reduction of $\mathbf{7 a}$ or $\mathbf{7 b}$ after the completion of self-assembly process in one pot with decent yields $(69 \%$ for $\mathbf{3 a}$ and $59 \%$ for $\mathbf{3 b}$, respectively).

To confirm the versatility of this approach to aminebased superphanes of interest, different variants of $m$ phthalaldehyde, viz. 2,6-pyridinedicarboxaldehyde (6c), 2,5-furandicarboxaldehyde (6d) and larger 4,4'-oxydibenzaldehyde (6e), were utilized to replace 6a. Expectedly, using a similar imine condensation strategy, compounds $\mathbf{3 b}$ 3e were successfully obtained by the simple one-pot selfassembly of hexakis-amine 5 with $\mathbf{6 c}, \mathbf{6 d}$ and $\mathbf{6 e}$, respectively, followed by in-situ reduction reactions in the presence of $\mathrm{NaBH}_{4}$ (Scheme S3). Of particular note is that, during the course of synthesis, no chromatography was needed for the purification of either $\mathbf{7 a - 7 e}$ or $\mathbf{3 a - 3 e}$. All imine-based superphanes $\mathbf{7 b} \mathbf{b} \mathbf{7 e}$ and amine-bearing superphanes $\mathbf{3 a -}$ 3e have been well characterized by ${ }^{1} \mathrm{H}$ NMR, ${ }^{13} \mathrm{C}$ NMR spectroscopy, and electrospray ionization high-resolution mass spectrometry (ESI-HRMS) (see supporting information).

Subsequently, the availability of this facile and concise synthetic approach to a wide range of amine-based superphanes was further examined by the demonstrative gramscale synthesis of superphane $\mathbf{3 c}$ in one pot. Concretely, the synthesis started from 2,6-pyridinedicarboxaldehyde 6c (1.27 g), which was subject to imine condensation with hexakis-amine 5 ( $2.36 \mathrm{~g})$ in methanol at $65^{\circ} \mathrm{C}$ for $12 \mathrm{~h}$. Then, the resulting mixtures with a substantial number of precipitates were in-situ treated with excess $\mathrm{NaBH}_{4}$ for a further $12 \mathrm{~h}$ at RT, where the precipitates disappeared gradually thereafter. After solvent removal, the resulting residuals were dispersed in water and repeatedly extracted with chloroform. The organic phases ware combined, dried, and evaporated to yield crude product, which was washed with excessive acetonitrile to offer $1.32 \mathrm{~g}$ of desired superphane $3 \mathbf{c}$ as a light yellow powders in $47 \%$ overall yield. 


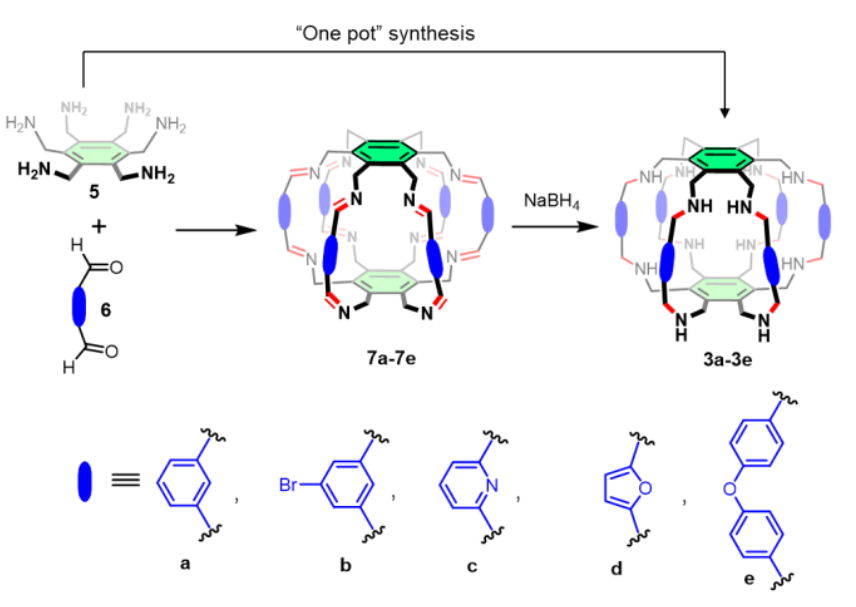

Scheme 1. Facile synthesis of dodecaimino-containing superphanes $\mathbf{7 a - 7 e}$, and the reduction of $\mathbf{7 a - 7 e}$ to prepare their corresponding dodecaazasuperphanes $\mathbf{3 a - 3 e}$ containing secondary amines.

\section{Post-functionalization}

Generally, post-synthetic functionalization of the core macrocycles or molecular cages has been ascertained to be a most effect synthetic route to access new analogues without a need to rework the synthesis of the core structures. ${ }^{37-}$ ${ }^{39}$ However, the binding properties of the core systems in question could be modulated with greater fidelity. With this in mind, we next sought to explore the post-functionalization of superphane 3c, for example, containing 12 NHs with alkyl halides. Initially, ethyl iodide (8a) was subject to reaction with 3c pretreated with $\mathrm{NaH}$ in DMF. As expected, the per-substituted product $\mathbf{4 a}$ was obtained in yield of $8 \%$ (Schemes 2 and S4). Given the fact that allyl and propargyl groups are two of the most commonly used functionalizable moieties for fabrication of functional molecules and materials via olefin metathesis, alkyne metathesis or click reactions, ${ }^{40-44}$ then commercially available allyl bromide $(\mathbf{8 b})$, propargyl bromide (8c) and 1-bromobut-2-yne bromide (8d) were utilized for direct modification of 3c. Specifically, treatment of $\mathbf{3 c}$ with excess allyl bromide in the presence of $\mathrm{NaOH}$ (in DMF) at $65^{\circ} \mathrm{C}$ for $20 \mathrm{~h}$ led to the expected perazasubstituted product $\mathbf{4 b}$ in $21 \%$ yield. Similarly, triple bond-containing groups proved capable of being incorporated into $\mathbf{3 c}$ via the electrophilic addition of $\mathbf{3 c}$ with excess propargyl bromide or 1-bromobut-2-yne bromide in the assistance of $\mathrm{NaH}$ (in DMF) at room temperature, offering 4c and $\mathbf{4 d}$ in yields of $11 \%$ and 5\%, respectively. Superphanes 4a-4d bearing 12 allyl substituents have been well characterized by ${ }^{1} \mathrm{H}$ NMR, ${ }^{13} \mathrm{C}$ NMR spectroscopy, and electrospray ionization high-resolution mass spectrometry (ESI-HRMS) (see supporting information). Interestingly, based on the ${ }^{1} \mathrm{H}$ NMR spectrum of $\mathbf{4 a - 4} \mathbf{d}$ in $\mathrm{CDCl}_{3}$ or DMSO$d_{6}$ at $298 \mathrm{~K}$, all three sets of methylene proton signals were found split, respectively, indicating that these methylene protons were distinguishable even at room temperature probably due to the restriction of intramolecular rotation of methylene units in question (Figures S1-S4).

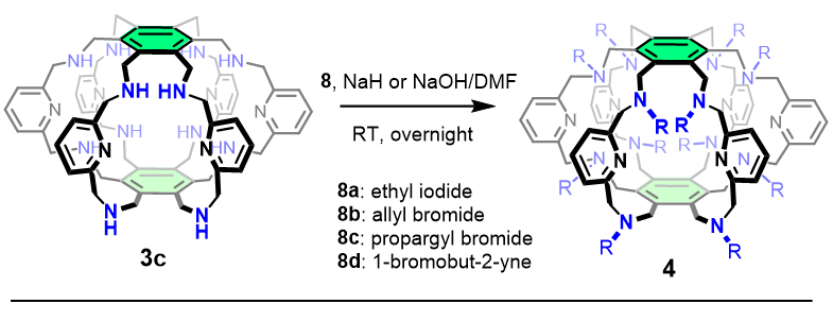

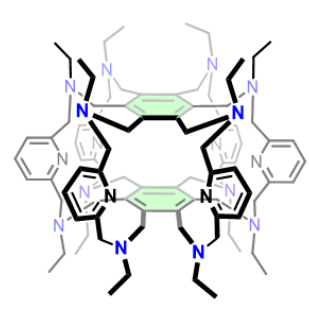

$4 a$

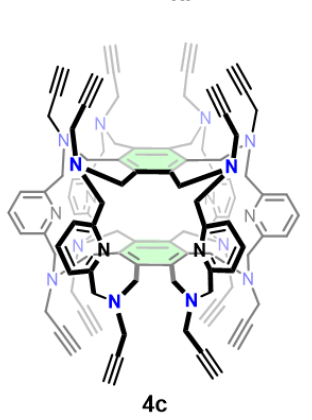

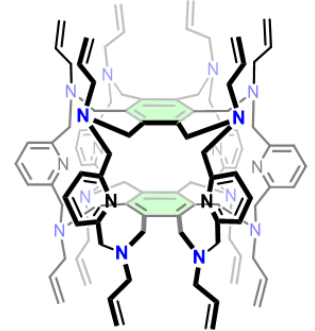

4b

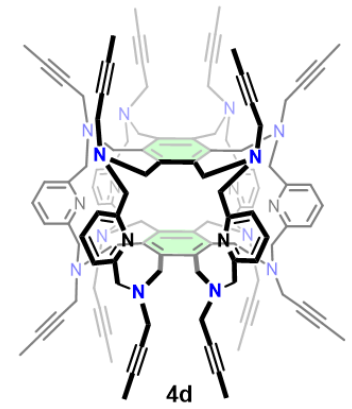

Scheme 2. Representative post-functionalization of superphane $3 \mathbf{c}$ with ethyl bromide $(\mathbf{8 a})$, allyl bromide (8b), propargyl bromide (8c), and 1-bromobut-2-yne (8d) and the chemical structures of $\mathbf{4 a - 4 d}$.

\section{Solid-state structures}

To obtain detailed insight into the structure, conformation, and potential binding properties of superphanes 3a-3e, substantial trials have been dedicated to growing their single crystals in either neutral form or protonated fashion. In the case of superphane 3c, many efforts have been made to grow single crystals of either $\mathbf{3 c}$ or its protonated form in the presence of strong acids, e.g. $\mathrm{HCl}, \mathrm{HBr}$, TsOH (4-methylbenzenesulfonic acid) and $\mathrm{CF}_{3} \mathrm{COOH}$, but to no avail. Much to our surprise, upon slowly diffusing acetone vapor into a solution of $\mathbf{3 c}$ in a mixture of chloroform and methanol in the presence of excess $\mathrm{CF}_{3} \mathrm{COOLi}$, colorless block-like single crystals suitable for X-ray single crystal structure analyses were obtained. Unexpectedly, the yielding crystal structure revealed a $2 \mathrm{CH}_{3} \mathrm{OH} @ 3 \mathbf{c} \cdot 2 \mathrm{H}^{+}$complex, instead of an expected $\mathrm{CF}_{3} \mathrm{COOLi}$ inclusion complex of $\mathbf{3 c}$. Although the exact locations of protons are usually not able to be identified by X-ray scattering, the diprotonated 3c could be deduced by the occurrence of two $\mathrm{CF}_{3} \mathrm{COO}^{-}$anions in each asymmetric unit (Figure S5). In the solid state, the framework of $3 \mathbf{c} \cdot 2 \mathrm{H}^{+}$displayed $D_{2 h}$ symmetry and a tunnel right through the center of the cage (Figure 2a). Unambiguously, one methanol molecule was observed to be entrapped within the center of $3 \mathbf{c}$ and the other one was clamped by two out of six pyridyl-containing bridges (Figures $2 \mathrm{~b}$ and S6). 

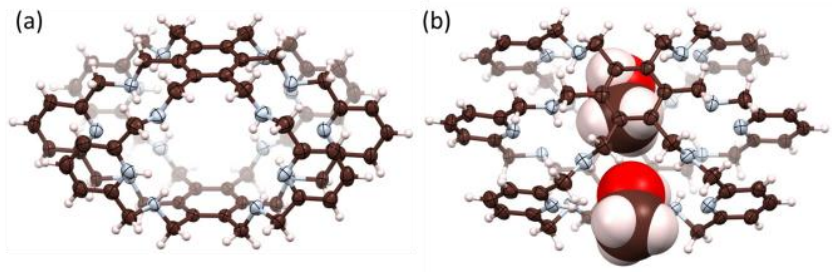

Figure 2. $\mathrm{X}$-ray single-crystal structures of (a) $\mathbf{3 c}$ in its protonated fashion; and (b) $2 \mathrm{CH}_{3} \mathrm{OH} @ 3 \mathbf{c} \cdot 2 \mathrm{H}^{+}$. The cages are presented in ellipsoid model while the entrapped methanol molecules are shown in space-filling form. All solvent molecules and other counter anions were omitted for clarity.

To elucidate the structure of the post modified superphane $\mathbf{4 b}$ with 12 allyl groups, suitable single crystals were obtained by slow diffusion of ethyl ether vapor into a solution of $\mathbf{4 b}$ in a mixture of $\mathrm{CH}_{3} \mathrm{OH}, \mathrm{CHCl}_{3}$ and $\mathrm{Et}_{2} \mathrm{O}$ at low temperature $\left(0 \sim 5{ }^{\circ} \mathrm{C}\right)$. The resulting crystal structure gave an expected super cage with exceptionally high symmetry (near $D_{6 h}$ ) (Figures $3 \mathrm{a}$ and $3 \mathrm{~b}$ ). Due to steric congestion, all allyl groups are oriented opposite to the core of superphane $\mathbf{4 b}$ to form two identical bowl-shaped outer cavities with the depth of $3.83 \AA$ (Figure S7). Meanwhile, the two faceto-face benzene rings are somewhat extruded to generate a close benzene $\cdot$.. benzene contact of $4.57 \AA$, indicating the occurrence of weak $\pi \cdots \pi$ interactions and the disappearance of internal void of $\mathbf{4 b}$. In this case, no solvent molecules were found within the internal cavity of superphane $\mathbf{4 b}$. Instead, an ethyl ether molecule was observed in each outer cavity formed by six allyl moieties as the fences (Figure S8). Each pyridinyl group at the periphery of $\mathbf{4 b}$ was aligned nearly perpendicular to the corresponding bridge plane and almost parallel to the other one at its opposite site. Interestingly, each $\mathbf{4 b}$ cage was found surrounded tightly by other six $\mathbf{4 b}$ molecules at the same plane via multiple cooperative $\mathrm{C}_{\mathrm{sp} 2}-\mathrm{H} \cdots \pi$, offset $\pi \cdots \pi$, and $\mathrm{C}_{\mathrm{sp} 3}-\mathrm{H} \cdots \pi$ interactions, giving rise to a regular hexagon with the side length of $14.23 \AA$ (Figures 3c and S9).

(a)

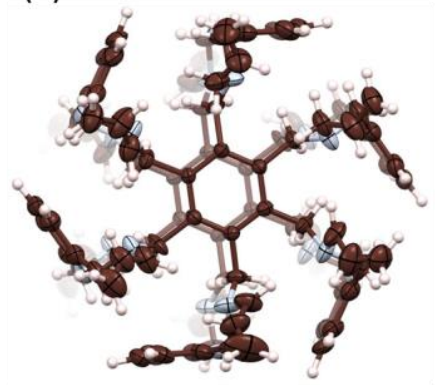

(b)

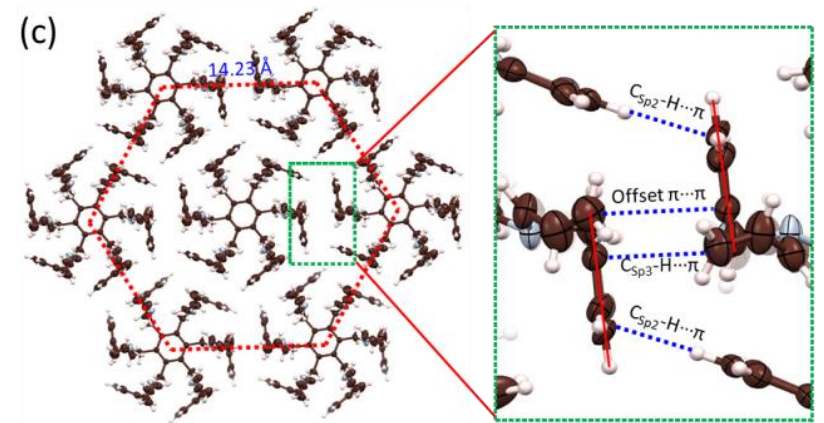

Figure 3. (a) Top view and (b) side view of single-crystal structure of $\mathbf{4 b}$ presented in ellipsoid model; (c) crystal packing of 4b with indicated interactions (insert). Solvent molecules were omitted for clarity.

In the case of propargyl-derived superphane $\mathbf{4 c}$, goodquality orthohexagonal single crystals were obtained by allowing the slow diffusion of ethyl ether vapor into a solution of 4c in ethyl acetate. The resulting crystal structure revealed a similar molecular conformation to what was seen in $\mathbf{4 b}$ as stated above (Figure $4 \mathrm{a}$ ). Briefly, the whole $\mathbf{4 c}$ molecule adopts a lantern-shaped conformation with a $D_{6 h}$ symmetry. The framework of $\mathbf{4 c}$ was fully compressed into a collapse cage with negligible void inside and a close benzene...benzene distance of $4.49 \AA$ (Figure S10). The six pyridyl-containing bridges are uniformly distributed around the core of $\mathbf{4 c}$. Each six propargyl groups on the top/bottom of the cage are found to form an external cavity. Two ethyl acetate molecules are captured within these two cavities, respectively, with a close distance of $3.58 \AA$ from $\mathrm{O}_{\text {sp2 }}$ of ethyl acetate to the corresponding benzene plane, indicating the occurrence of lone pair $\cdots \pi$ interactions (Figures $4 \mathrm{~b}$ and S11). Again, each 4c unit was found to interact with other six adjacent cages, forming a pseudo regular hexagon via multiple $\mathrm{C}-\mathrm{H} \cdots \pi$ and $\pi \cdots \pi$ interactions. In a similar fashion, a perfect 2D network was formed by the self-assembly of 4c (Figures S12 and S13). (a)

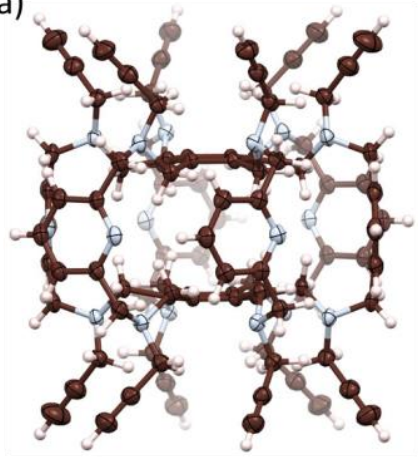

(b)

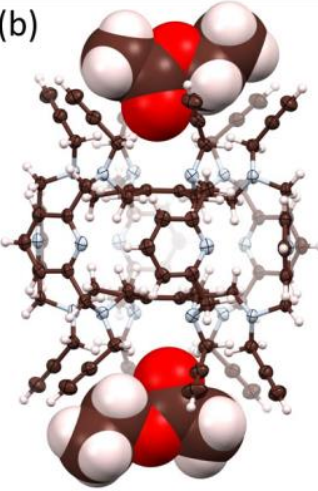

Figure 4. Views of single-crystal structure of (a) $4 c$ and (b) 4c.2ethylacetate presented in ellipsoid model. Other solvent molecules were omitted for clarity.

\section{Photophysical Properties}

Fluorescence is a property of matter that is critical for many research fields, such as chemistry, biology, material science and the like. ${ }^{45}$ The marriage of macrocycles or cages and fluorescence has garnered growing interest of the chemists in recent years. ${ }^{46-47}$ Interestingly, although no specific fluorofores were integrated, genuine blue-green fluorescent emissions were observed when chloroform solutions of 3c, 3d and 3e were exposed to 365-nm UV light (Figure 5a, inset). Upon excitation of $\mathbf{3 c}$, 3d, and $\mathbf{3 e}$ in chloroform at 340, 373, and $367 \mathrm{~nm}$, respectively, they showed similar emission bands of $400 \sim 600 \mathrm{~nm}$ with an emission maxima at 452, 449, and $439 \mathrm{~nm}$, respectively (Figures S14S16). Due to the poor solubility of $\mathbf{3 a}$ and $\mathbf{3 b}$ in commonly used solvents, they were subject to protonation with $\mathrm{HCl}$ and the resulting salts were found soluble in DMSO. Upon excitation of the protonated 3a, 3b in DMSO at 365 and 376 
nm, respectively, emission bands of 400 600 nm with corresponding emission maxima at 443 and $442 \mathrm{~nm}$ were seen (Figures S17 and S18). Notably, all of these superphanes in solution displayed poor fluorescence quantum yields $\left(\Phi_{\mathrm{f}}<\right.$ 0.01). In contrast, both imino-based superphanes $7 \mathbf{a}-\mathbf{7 c}, \mathbf{7 e}$ and tertiary amine-based superphanes $4 \mathbf{a}-4 \mathbf{d}$ in solutions proved nearly fluorescence-silent. These findings indicated that the observed weak emission of $\mathbf{3 a}-\mathbf{3 e}$ in solution might be attributed to an intramolecular proton transfer mechanism.

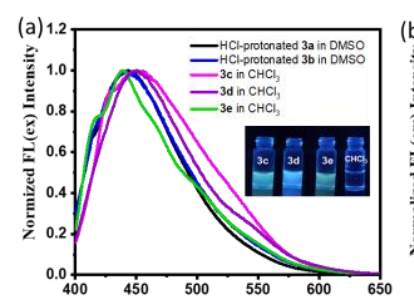

(c)

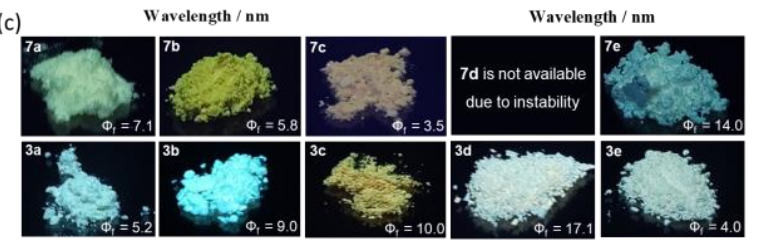

Figure 5. (a) Fluorescent spectra of $\mathbf{3 a}$ and $\mathbf{3 b}$ in their HCl-protonated form in DMSO and $\mathbf{3 c}-\mathbf{3 e}$ in $\mathrm{CHCl}_{3}$. Insert: Photos of liquid fluorescence of 3a-3c in chloroform; (b) Normalized fluorescent spectra in the solid state of $7 \mathbf{a}-\mathbf{7 c}, 7 \mathbf{e}$ and $3 \mathbf{a}-\mathbf{3 e}$; (c) photos of solid fluorescence in the solid state of $\mathbf{7 a - 7 c}, \mathbf{7 e}$ and 3a-3e.

Interestingly, as opposed to the weak/non-fluorescent features in solution, relatively strong solid-state fluorescent emission of the imino-based compounds $\mathbf{7 a - 7 c}$, and 7e was observed (Figure $5 b$ ). Specifically, when exited with light at 433, 446, 497 and $446 \mathrm{~nm}$ for $\mathbf{7 a}, \mathbf{7 b}, \mathbf{7 c}$, and $7 \mathbf{e}$, respectively, their solid samples emitted strong visible fluorescent light with the corresponding emission maxima at 505, 517, 551 and $527 \mathrm{~nm}$ (Figures S19-S22). Similarly, the secondary amine-based superphanes $\mathbf{3 a - 3 e}$ in solid state also exhibited relatively strong fluorescence with the emission maxima ranging from $439 \mathrm{~nm}$ to $549 \mathrm{~nm}$ (Figure S23S27). Structurally, compounds 7a-7e, inter alia the former four, are quite similar. Nevertheless, their solid-state emitting color differs from one another significantly ranging from chartreuse to near white with fluorescence quantum yields $\left(\Phi_{\mathrm{f}}\right)$ of $7.1,5.8,3.5$ and 14.0 for $\mathbf{7 a}, \mathbf{7 b}, \mathbf{7} \mathbf{c}$ and $\mathbf{7 e}$, respectively (Figure $5 c$ ). Likewise, cages $\mathbf{3 a - 3 e}$ as powders emit near white, blueing, yellowish, near-white, and white fluorescence, respectively, with the corresponding fluorescent quantum yields of 5.2, 9.0, 10.0, 17.1 and 4.0. Taken together, based on the framework of superphane, a series of emissive fluorescent super cages were easily obtained via incorporating various substituents into the bridges between the top and bottom benzene rings. The acquired fluorescence could be finely designed and tuned by modifying the bridges with specific units or by reducing the imine bonds of the superphanes. To the best of our knowledge, this is the first report on superphane systems featuring tunable fluorescent emission. Given the weak solution-state emission and strong solid-state fluorescence, these findings might be somewhat rationalized by aggregation induced emission (AIE) effect. ${ }^{48}$ However, more experimental and theoretical studies are needed to shed light on the detailed mechanism, inter alia, involving the unusual (near-) white emission.

\section{Host-guest properties}

Cryptands and aza-cryptands have been well-established to work as versatile anionic receptors for negatively charged guest species, inter alia, in their protonated form. ${ }^{49}$ Inspired by those findings in the literature, a selected example, 3a containing 12 NH units, was subject to protonation with strong acids, e.g. hydrochloric acid and $\mathrm{H}_{2} \mathrm{SO}_{4}$. Specifically, superphane 3a proves not soluble in commonly used solvents, but it becomes soluble in either DMSO or a mixture of DMSO and water $(5: 1, v / v)$ and only one set of resonances were observed upon treatment of $\mathbf{3 a}$ with excess $\mathrm{HCl}$ or $\mathrm{H}_{2} \mathrm{SO}_{4}$ (Figures S28 and S29). These findings allow us to suggest that 3a was capable of being fully protonated with $\mathrm{HCl}$ or $\mathrm{H}_{2} \mathrm{SO}_{4}$ in relatively flexible conformation at $298 \mathrm{~K}$.

We next sought to explore whether $\mathrm{NH}$-bearing superphanes 3a in its protonated manners could serve as a receptor for binding anions, such as $\mathrm{Cl}^{-}$. Initial evidence for anion encapsulation of protonated $\mathbf{3 a}$ came from the single crystal $\mathrm{X}$-ray structure of its hydrochloric complex. Specifically, suitable crystals were obtained by allowing a solution of $\mathrm{HCl}$-protonated $\mathbf{3 a}$ in water to evaporate slowly at room temperature. The resulting crystal structure revealed a protonated complex in the solid state (Figure 6a). Due to the limitations of crystallography and the disorder of the solvent molecules and the counter chloride outside the cavity, the degree of protonation of $\mathbf{3 a}$ was not able to be exactly determined. In terms of the structure of protonated $\mathbf{3 a}$, the two face-to-face benzene rings are clamped parallel on top of each other by six bridges bearing $m$-xylylenediamine moieties and the six toroidal bridges are almost uniformly distributed around the internal cavity, generating a lantern-like superstructure (Figures S30 and S31). Notably, each bridge of superphane $\mathbf{3 a}$ has at least two NHs and one $\mathrm{Ar}-\mathbf{H}$ as the binding sites, pointing to the inside cavity. These enable protonated 3a to feature a unique supramolecular receptor for binding specific guests with up to 18 hydrogen bonding donors. Interestingly, a closer inspection at this crystal structure revealed that a trimeric cluster consisting of two $\mathrm{Cl}^{-}$anions and one $\mathrm{H}_{2} \mathrm{O}$ molecule were found embedded right within the cavity of $\mathbf{3 a}$, wherein the $\mathrm{Cl}^{-} \cdots \mathrm{Cl}^{-}$ and averaged $\mathrm{Cl}^{-} \cdots \mathrm{O}$ (water) distances were measured to be 4.15 and $3.19 \AA$, respectively (Figures $6 \mathrm{~b}$ and S32). Each hydrogen atom of the water molecule points to one chloride anion, leading to a $\mathrm{Cl}^{-} \cdots \mathrm{H}-\mathrm{O}-\mathrm{H}^{\prime} \cdot \mathrm{Cl}^{-}$complex, which as a whole was stabilized by multiple hydrogen bonds. 

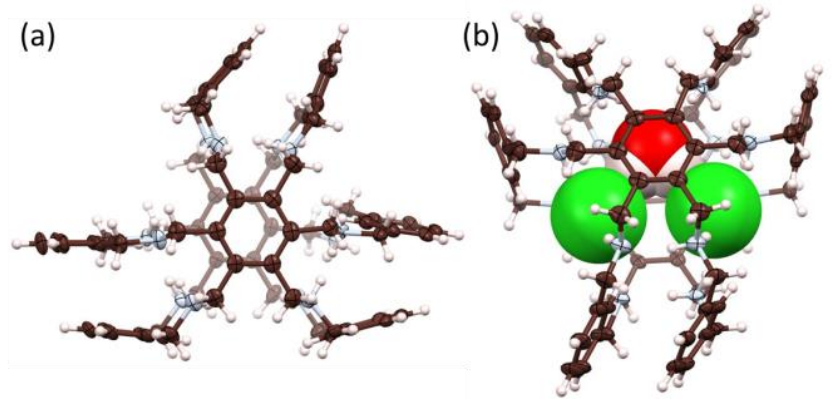

Figure 6. X-ray single-crystal structures of (a) 3a in its protonated form; (b) $2 \mathrm{Cl}^{-} \cdot \mathrm{H}_{2} \mathrm{O} @ 3 \mathbf{3 a}$ (protonated). The superphane frameworks are presented in ellipsoid model while the entrapped guest species, e.g. $\mathrm{Cl}^{-}$and $\mathrm{H}_{2} \mathrm{O}$, are shown in space-filling form. All solvent molecules and other counter anions were omitted for clarity.

The ability of protonated 3a to bind chloride in solution was further probed via ${ }^{1} \mathrm{H}$ NMR spectroscopy using a mixture of DMSO- $d_{6}$ and $\mathrm{D}_{2} \mathrm{O}(5: 1, \mathrm{v} / \mathrm{v})$ as the solvent. As discussed above, spectroscopic analysis of the $\mathrm{H}_{2} \mathrm{SO}_{4}$ protonated 3a revealed only one set of resonance signals in the complex, indicating that the dominant species is $\mathbf{3 a} \cdot \mathrm{H}_{12}{ }^{12+}$, with all secondary amino groups protonated (Figure 5c). Of particular note is that the aromatic $\mathrm{C}_{\mathrm{sp} 2}-\mathbf{H}_{e}$ in protonated 3a was observed to be located at $6.55 \mathrm{ppm}, \mathrm{a}$ relatively upfield region, presumably suggesting that no counter sulfate anion was captured within the central cavity of 3a (Figure S33). However, upon addition of excess $\mathrm{Cl}^{-}$(as its TBA salt) to a $1.0 \mathrm{mM}$ solution of $\mathrm{H}_{2} \mathrm{SO}_{4}$-protonated $\mathbf{3 a}$, the broad singlet associated with the $\mathrm{C}_{\mathrm{sp} 2}-\mathbf{H}$ protons seen at $6.55 \mathrm{ppm}(\boldsymbol{e})$ underwent a pronounced downshift to 7.01 ppm. Meanwhile, the aromatic $\mathrm{C}_{\mathrm{sp} 2}-\mathrm{H}$ protons at $7.02(\boldsymbol{c})$ and $6.93(\boldsymbol{d})$ suffered a shift to 6.91 and $6.76 \mathrm{ppm}$, respectively, and the methylene protons showed chemical shift changes from $4.43(\boldsymbol{a})$ and $4.04 \mathrm{ppm}(\boldsymbol{b})$ to 4.51 and 4.23 ppm, respectively (Figure S33). These findings led us to suggest that protonated superphane $3 \mathbf{a}$ binds effectively the $\mathrm{Cl}^{-}$ anion well in solution.

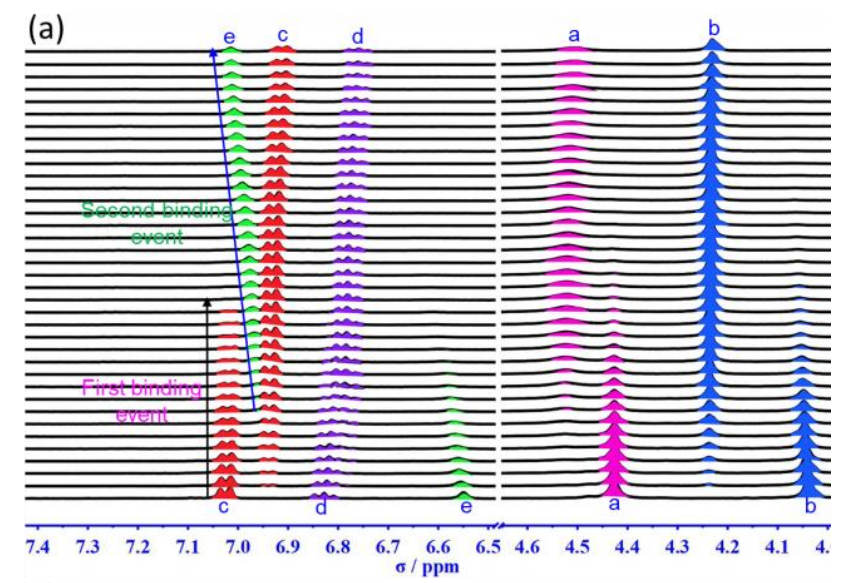

(b)

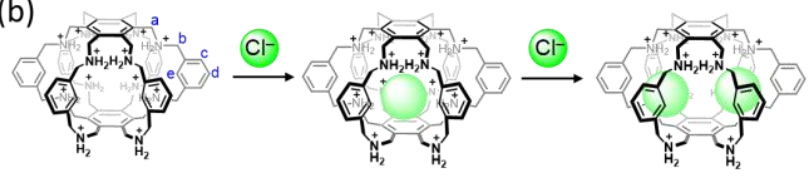

Figure 7. (a) selected regions of ${ }^{1} \mathrm{H}$ NMR spectra (DMSO$d_{6} / \mathrm{D}_{2} \mathrm{O}, 5: 1, \mathrm{v} / \mathrm{v}, 298 \mathrm{~K}$ ) acquired during the titration of $\mathrm{H}_{2} \mathrm{SO}_{4}-$ protonated 3a with increasing quantities of TBACl: (bottom to top) $0,0.25,0.5,0.75,1.0,1.25,1.5,1.75,2.0,2.25,2.5,2.75,3.0$, 3.25 , 3.5, 3.75, 4.0, 4.25, 4.5, 4.75, 5.0, 5.5, 6.0, 6.5, 7.0, 8.0, 9.0, $10.0,11.0,13.0,15.0,17.0,19.0,23.0,27.0,31.0$, and 35.0 equiv; (b) A schematic view of the chloride binding by $\mathbf{3 a} \cdot \mathrm{H}_{12}{ }^{12+}$.

To obtain greater insights into the binding of chloride by protonated 3a, ${ }^{1} \mathrm{H}$ NMR spectroscopic titrations were carried out in a mixture of DMSO- $d_{6}$ and $\mathrm{D}_{2} \mathrm{O}(5: 1, \mathrm{v} / \mathrm{v})$ using $\mathrm{TBACl}$ as the chloride anion source (Figure $7 \mathrm{a}$ ). Specifically, upon incremental addition of $0 \sim 4$ equivalents of $\mathrm{Cl}^{-}$, all proton signals ascribable to protonated $3 \mathbf{a}$ were observed to gradually decrease while a new set of resonances progressively increase, reflecting the first chloride binding event in slow exchange on the NMR time scale. Interestingly, apart from the increase, the new set of signals (e.g. $\boldsymbol{e}$ ) corresponding to the chloride complex simultaneously underwent either downfield or upfield shifts regardless of the first saturation point achieved, presumably indicating the second chloride binding event in fast exchange on the NMR time scale. Consequently, the binding constants of $K_{11}=(1.8 \pm 0.3)$ $\times 10^{3}$ and $K_{12}=(1.1 \pm 0.1) \times 10^{3} \mathrm{M}^{-1}$ can be estimated by fitting the ${ }^{1} \mathrm{H}$ NMR data corresponding to the $\mathrm{C}_{\mathrm{sp} 2}-\mathbf{H}_{c}, \mathrm{C}_{\mathrm{sp} 2}-$ $\mathbf{H}_{d}$, and $\mathrm{C}_{\mathrm{sp} 2}-\mathbf{H}_{e}$ proton resonances to a 1:2 binding model (Figure S34). These findings allowed us to conclude that the fully protonated 3a was probably capable of encapsulating two chloride anions, as reflected in the single crystal structure mentioned above.

A careful inspection of the ${ }^{1} \mathrm{H}$ NMR spectrum of HCl-protonated 3a in DMSO- $d_{6}$ at room temperature revealed the occurrence of a broad singlet around $8.47 \mathrm{ppm}$, which was able to be deuterated with $\mathrm{D}_{2} \mathrm{O}$ within $30 \mathrm{~min}$, reflecting the active role of protons in question (Figure S35). In contrast, no such active protons were seen in the case of $\mathrm{H}_{2} \mathrm{SO}_{4-}$ protonated 3a in a mixture of DMSO- $d_{6}$ and $\mathrm{H}_{2} \mathrm{O}(5: 1, \mathrm{v} / \mathrm{v})$. However, upon addition of excess TBACl to the beforementioned solution, a broad singlet at $8.50 \mathrm{ppm}$ occurred (Figure S36). These observations led us to suggest that water molecules might get involved in the binding of the chloride dimer, resulting a possible complexation of a $\mathrm{Cl}^{-} \cdots \mathrm{H}-\mathrm{O}-$ $\mathrm{H} \cdot \mathrm{Cl}^{-}$cluster in solution as observed in the single crystal structure.

\section{Conclusion}

In summary, a series of dodecaazasuperphanes, featuring exceptionally high $\left(D_{6 h}\right)$ symmetry and multiple (up to 18) binding sites, have been firstly established via a facile and efficient in-situ reductive amination strategy. The structural diversity could be achieved by the pre-modification of the dialdehydes. To the best of our knowledge, this is the first paper to describe the concise, easy-to-operate and gram-scale synthesis of superphanes, which opens up the door to superphane chemistry. Furthermore, the feasible post-modification of secondary amine-based superphanes was exemplified by furnishing superphane $\mathbf{3 e}$ with various functional groups, viz. ethyl, allyl, propargyl and but-2-yn1-yl. Importantly, compounds $\mathbf{7 a - 7 e}$ and $\mathbf{3 a - 3 e}$ under study were found to exhibit solid-state fluorescence with various emission colors ranging from bluish to near white. Meanwhile, 3a-3e proved emissive in solution as well. 
These represent the first fluorescence emissive superphane systems. Last but not least, with suitable internal apertures and appropriate binding sites as demonstrated by crystallography, and ${ }^{1} \mathrm{H}$ NMR spectroscopy, superphane $\mathbf{3 a}$ in its protonated manners proved able to capture a $2 \mathrm{Cl}^{-} \cdot \mathrm{H}_{2} \mathrm{O}$ cluster both in the solid state and in solution. This work establishes a facile and efficient synthetic approach to emissive superphanes that could be broadly utilized a new class of advanced emissive materials or as a new generation of supramolecular hosts for neutral species, anions, cations, ion pairs, as well as labile ionic solvate clusters. Further studies are ongoing in our lab to advance our understanding of superphane chemistry and will be published in due course.

\section{ASSOCIATED CONTENT}

\section{Supporting Information}

This material is available free of charge via the Internet at http://pubs.acs.org."

Experimental procedures, NMR spectroscopic studies, HRMS results, fluorescent spectroscopic details, and $\mathrm{X}$-ray structural data for 3c-TFA, 4b, 4c, and $2 \mathrm{Cl}^{-} \cdot \mathrm{H}_{2} \mathrm{O} @ 3 \mathbf{a}$ complex (PDF)

$\mathrm{X}$-ray crystallographic data for 3c-TFA (CIF)

$\mathrm{X}$-ray crystallographic data for $\mathbf{4 b}$ (CIF)

$\mathrm{X}$-ray crystallographic data for $\mathbf{4 c}$ (CIF)

$\mathrm{X}$-ray crystallographic data for $2 \mathrm{Cl}^{-} \cdot \mathrm{H}_{2} \mathrm{O} @ 3$ a complexes (CIF)

\section{AUTHOR INFORMATION}

\section{Corresponding Author}

* Qing He: heqing85@hnu.edu.cn

\section{Declaration of Interests}

Hunan University has applied for a patent on this work.

\section{ACKNOWLEDGMENT}

This research was funded by the National Natural Science Foundation of China (22071050 and 21901069 to Q. H.), the Science and Technology Plan Project of Hunan Province, China (Grant No. 2019RS1018 to Q. H.), and Fundamental Research Funds for the Central Universities (Startup Funds to Q. H.). We thank Dr Zhenyi Zhang from Bruker (Beijing) Scientific Technology Co., Ltd for helpful discussions on X-ray crystallography.

\section{REFERENCES}

1. Cram, D. J.; Steinberg, H., Macro Rings. I. Preparation and Spectra of the Paracyclophanes. J. Am. Chem. Soc. 1951, 73, 56915704.

2. Gleiter, R.; Hopf, H., Modern Cyclophane Chemistry. Wiley: New York, 2004.

3. cram, D. J.; Cram, J. M., Cyclophane chemistry: bent and battered benzene rings. Acc. Chem. Res. 1971, 4, 204-213.

4. Morisaki, Y.; Chujo, Y., Cyclophane-containing polymers. Prog. Polym. Sci. 2008, 33, 346-364.

5. Nozawa, R.; Kim, J.; Oh, J.; Lamping, A.; Wang, Y. M.; Shimizu, S.; Hisaki, I.; Kowalczyk, T.; Fliegl, H.; Kim, D.; Shinokubo, H., Three-dimensional aromaticity in an antiaromatic cyclophane. Nat. Commun. 2019, 10.

6. Gulder, T.; Baran, P. S., Strained cyclophane natural products: Macrocyclization at its limits. Nat. Prod. Rep. 2012, 29, 899-934. 7. Ramaiah, D.; Neelakandan, P. P.; Nair, A. K.; Avirah, R. R., Functional cyclophanes: Promising hosts for optical biomolecular recognition. Chem. Soc. Rev. 2010, 39, 4158-4168.
8. Ghasemabadi, P. G.; Yao, T. G.; Bodwell, G. J., Cyclophanes containing large polycyclic aromatic hydrocarbons. Chem. Soc. Rev. 2015, 44, 6494-6518.

9. Vögtle, F.; Neumann, P., Stereochemistry of [2.2]Metacyclophanes. Angew. Chem. Int. Ed. 1972, 11, 73-83.

10. Sekine, Y.; Brown, M.; Boekelheide, V., [2.2.2.2.2.2] $(1,2,3,4,5,6)$ Cyclophane: superphane. J. Am. Chem. Soc. 1979, 101, 3126-3127.

11. Gleiter, R.; Kratz, D., "Super" phanes. Acc. Chem. Res. 1993, 26, 311-318.

12. Sakamoto, Y.; Miyoshi, N.; Hirakida, M.; Kusumoto, S.; Kawase, H.; Rudzinski, J. M.; Shinmyozu, T., Multibridges (3N) syclophanes. 4. Syntheses, structures, and transannular pi-pi interactions of multibridged [3(n)]cyclophanes. J. Am. Chem. Soc. 1996, 118, 12267-12275.

13. El-tamany, S.; Hopf, H., Eine zweite Synthese von [26](1,2,3,4,5,6)Cyclophan (Superphan). Chem. Ber. 1983, 116, $1682-1685$.

14. Ogoshi, T.; Yamagishi, T. A.; Nakamoto, Y., Pillar-Shaped Macrocyclic Hosts Pillar[n]arenes: New Key Players for Supramolecular Chemistry. Chem. Rev. 2016, 116, 7937-8002.

15. Rizzuto, F. J.; von Krbek, L. K. S.; Nitschke, J. R., Strategies for binding multiple guests in metal-organic cages. Nat. Rev. Chem. 2019, 3, 204-222.

16. Hasell, T.; Cooper, A. I., Porous organic cages: soluble, modular and molecular pores. Nat. Rev. Mater. 2016, 1.

17. Wang, M. X., Coronarenes: recent advances and perspectives on macrocyclic and supramolecular chemistry. Sci. China Chem. 2018, 61, 993-1003.

18. He, Q.; Vargas-Zuniga, G. I.; Kim, S. H.; Kim, S. K.; Sessler, J. L., Macrocycles as Ion Pair Receptors. Chem. Rev. 2019, 119, 9753-9835.

19. Boehr, D. D.; Nussinov, R.; Wright, P. E., The role of dynamic conformational ensembles in biomolecular recognition. Nat. Chem. Biol. 2009, 5, 789-796.

20. Pugh, G. C.; Burns, J. R.; Howorka, S., Comparing proteins and nucleic acids for next-generation biomolecular engineering. Nat. Rev. Chem. 2018, 2, 113-130.

21. Liu, Y.; Zhao, W.; Chen, C. H.; Flood, A. H., Chloride capture using a C-H hydrogen-bonding cage. Science 2019, 365, 159-161. 22. Edwards, S. J.; Valkenier, H.; Busschaert, N.; Gale, P. A.; Davis, A. P., High-Affinity Anion Binding by Steroidal Squaramide Receptors. Angew. Chem. Int. Ed. 2015, 54, 45924596.

23. Segura, J. L.; Royuela, S.; Ramos, M. M., Post-synthetic modification of covalent organic frameworks. Chem. Soc. Rev. 2019, 48, 3903-3945.

24. Zhang, W.; Jin, Y., Dynamic Covalent Chemistry: Principles, Reactions, and Applications. Wiley-VCH: Weinheim, 2017.

25. Jin, Y. H.; Yu, C.; Denman, R. J.; Zhang, W., Recent advances in dynamic covalent chemistry. Chem. Soc. Rev. 2013, 42, 6634 6654 .

26. Chen, L.; Chen, Q. H.; Wu, M. Y.; Jiang, F. L.; Hong, M. C., Controllable Coordination-Driven Self-Assembly: From Discrete Metallocages to Infinite Cage-Based Frameworks. Acc. Chem. Res. 2015, 48, 201-210.

27. Greenaway, R.; Santolini, V.; Bennison, M. J.; Alston, B. M.; Pugh, C. J.; Little, M. A.; Miklitz, M.; Eden-Rumps, E. G. B.; Clowes, R.; Shakil, A.; Cuthbertson, H. J.; Armstrong, H.; Briggs, M. E.; Jelfs, K. E.; Cooper, A. I., High-throughput discovery of organic cages and catenanes using computational screening fused with robotic synthesis. Nat. Commun. 2018, 9, 2849.

28. Lauer, J. C.; Zhang, W. S.; Rominger, F.; Schroder, R. R.; Mastalerz, M., Shape-Persistent [4+4] Imine Cages with a Truncated Tetrahedral Geometry. Chem. Eur. J. 2018, 24, 18161820. 
29. Wagner, P.; Rominger, F.; Zhang, W. S.; Gross, J. H.; Elbert, S. M.; Schroder, R. R.; Mastalerz, M., Chiral Self-sorting of Giant Cubic [8+12] Salicylimine Cage Compounds. Angew. Chem. Int. Ed. 2021, 60, 8896-8904.

30. Acharyya, K.; Mukherjee, P. S., Organic Imine Cages: Molecular Marriage and Applications. Angew. Chem. Int. Ed. 2019, $58,8640-8653$.

31. He, Q.; Li, A.; Xiong, S.; Zhou, W.; Zhai, H.; Liu, Y., Superphanes: Old Yet New Binding-Agents for Highly Selective Recognition of Fluoride by Size-Sieving Effect. ChemRxiv. Preprint 2020, DOI: 10.26434 /chemrxiv.13489608.v1.

32. Li, A. M.; Xiong, S. L.; Zhou, W.; Zhai, H. J.; Liu, Y. C.; He, Q., Superphane: a new lantern-like receptor for encapsulation of a water dimer. Chem. Commun. 2021.

33. Xie, H.; Finnegan, T. J.; Liyana Gunawardana, V. W.; Pavlović, R. Z.; Moore, C. E.; Badjić, J. D., A Hexapodal Capsule for the Recognition of Anions. J. Am. Chem. Soc. 2021, 143, 3874-3880. 34. De Rycke, N.; Marrot, J.; Couty, F.; David, O. R. P., Synthesis and characterization of hexasubstituted azacryptands. Tetrahedron Lett. 2010, 51, 6521-6525.

35. Schick, T. H. G.; Lauer, J. C.; Rominger, F.; Mastalerz, M., Transformation of Imine Cages into Hydrocarbon Cages. Angew. Chem. Int. Ed. 2019, 58, 1768-1773.

36. Gayen, K. S.; Das, T.; Chatterjee, N., Recent Advances in TrisPrimary Amine Based Organic Imine Cages and Related Amine Macrocycles. Eur. J. Org. Chem. 2021, 2021, 861-876.

37. Cafeo, G.; Kohnke, F. H.; La Torre, G. L.; White, A. J. P.; Williams, D. J., From Large Furan-Based Calixarenes to Calixpyrroles and Calix[n]furan[m]pyrroles: Syntheses and Structures. Angew. Chem. Int. Ed. 2000, 39, 1496-1498.

38. Wang, M. X., Nitrogen and Oxygen Bridged Calixaromatics: Synthesis, Structure, Functionalization, and Molecular Recognition. Acc. Chem. Res. 2012, 45, 182-195.

39. Guo, Q.-H.; Zhao, L.; Wang, M.-X., Synthesis and Molecular Recognition of Water-Soluble S6-Corona[3]arene[3]pyridazines. Angew. Chem. Int. Ed. 2015, 54, 8386-8389.
40. Hoveyda, A. H.; Zhugralin, A. R., The remarkable metalcatalysed olefin metathesis reaction. Nature 2007, 450, 243-251.

41. Fürstner, A., Olefin Metathesis and Beyond. Angew. Chem. Int. Ed. 2000, 39, 3012-3043.

42. Grubbs, R. H., Olefin-metathesis catalysts for the preparation of molecules and materials (Nobel lecture). Angew. Chem. Int. Ed. 2006, 45, 3760-3765.

43. Furstner, A., Alkyne Metathesis on the Rise. Angew. Chem. Int. Ed. 2013, 52, 2794-2819.

44. Durmaz, H.; Sanyal, A.; Hizal, G.; Tunca, U., Double click reaction strategies for polymer conjugation and postfunctionalization of polymers. Polym. Chem. 2012, 3, 825-835. 45. Goldys, E. M., Fluorescence Applications in Biotechnology and Life Sciences. John Wiley \& Sons, Inc.: Hoboken, NJ, 2009.

46. Zheng, X. J.; Zhu, W. C.; Zhang, C.; Zhang, Y.; Zhong, C.; Li, H.; Xie, G. H.; Wang, X. J.; Yang, C. L., Self-Assembly of a Highly Emissive Pure Organic Imine-Based Stack for Electroluminescence and Cell Imaging. J. Am. Chem. Soc. 2019, 141, 4704-4710.

47. Duan, H. H.; Li, Y. W.; Li, Q. F.; Wang, P. P.; Liu, X. R.; Cheng, L.; Yu, Y.; Cao, L. P., Host-Guest Recognition and Fluorescence of a Tetraphenylethene-Based Octacationic Cage. Angew. Chem. Int. Ed. 2020, 59, 10101-10110.

48. Hong, Y.; Lam, J. W. Y.; Tang, B. Z., Aggregation-induced emission. Chem. Soc. Rev. 2011, 40, 5361-5388.

49. Kang, S. O.; Llinares, J. M.; Day, V. W.; Bowman-James, K., Cryptand-like anion receptors. Chem. Soc. Rev. 2010, 39, 39804003. 
Insert Table of Contents artwork here
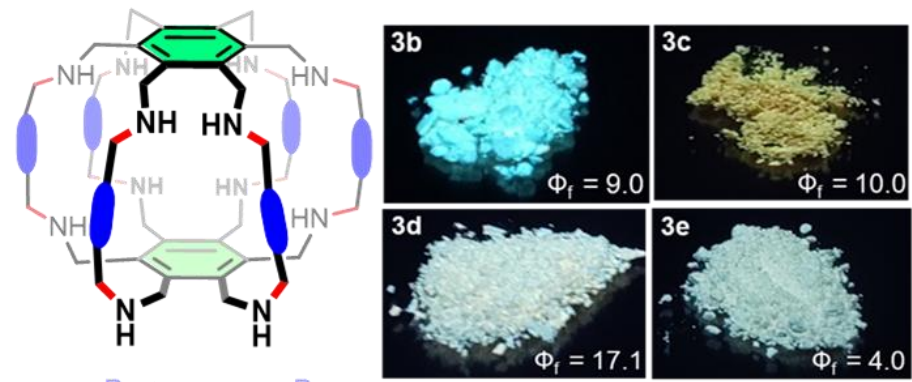

$\checkmark \quad$ Facile synthesis

$\checkmark$ Gram-scale preparation

$\checkmark$ Pre-modification

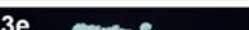

$\checkmark$ Post-functionalization

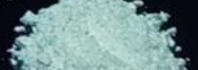

3.

$\checkmark$ Chromatography free

$\checkmark \quad$ Structural diversity
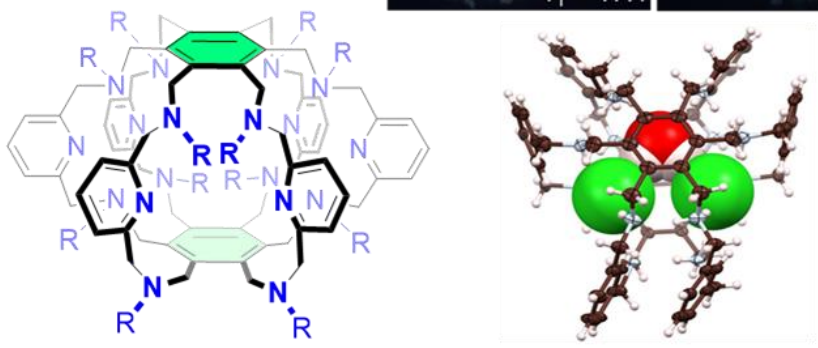

$\checkmark \quad$ High symmetry

$\checkmark \quad$ Liquid fluorescence

$\checkmark$ Solid-state fluorescence

$\checkmark \quad$ Up to 18 binding sites

$\checkmark$ Near-closed 3D cavity

$\checkmark \quad$ Unique host-guest binding 